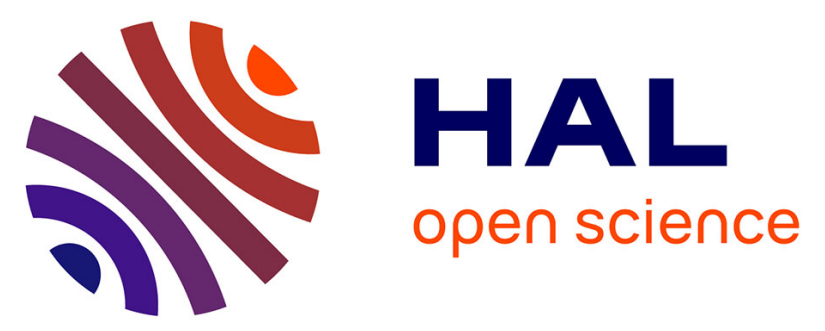

\title{
Synthesis and characterization of thiophene-based push-pull chromophores for tuning the electrical and optical properties of surfaces with controlled SAM formation
}

Volodymyr Malytskyi, Virginie Gadenne, Younal Ksari, Lionel Patrone, Jean-Manuel Raimundo

\section{To cite this version:}

Volodymyr Malytskyi, Virginie Gadenne, Younal Ksari, Lionel Patrone, Jean-Manuel Raimundo. Synthesis and characterization of thiophene-based push-pull chromophores for tuning the electrical and optical properties of surfaces with controlled SAM formation . Tetrahedron, 2017, 73 (39), pp.57385744. 10.1016/j.tet.2017.08.004 . hal-01794687

\section{HAL Id: hal-01794687 \\ https://hal.science/hal-01794687}

Submitted on 17 May 2018

HAL is a multi-disciplinary open access archive for the deposit and dissemination of scientific research documents, whether they are published or not. The documents may come from teaching and research institutions in France or abroad, or from public or private research centers.
L'archive ouverte pluridisciplinaire HAL, est destinée au dépôt et à la diffusion de documents scientifiques de niveau recherche, publiés ou non, émanant des établissements d'enseignement et de recherche français ou étrangers, des laboratoires publics ou privés. 


\title{
Synthesis and characterization of thiophene-based push-pull chromophores for tuning the electrical and optical properties of surfaces with controlled SAM formation
}

\author{
Volodymyr Malytskyi $^{\mathrm{a}, \mathrm{b}}$, Virginie Gadenne ${ }^{\mathrm{b}, \mathrm{c}}$, Younal Ksari ${ }^{\mathrm{b}}$, Lionel Patrone ${ }^{\mathrm{b}, \mathrm{c} *}$, Jean-Manuel \\ Raimundo $^{\text {a* }}$ \\ ${ }^{a}$ Aix Marseille Univ, CNRS, CINaM UMR 7325, Campus de Luminy, case 913, 13288 Marseille cedex 09, France. \\ ${ }^{b}$ Aix Marseille Univ, Université de Toulon, CNRS, IM2NP UMR 7334, Campus St Jérôme, 13397 Marseille cedex 20 , France. \\ ${ }^{c}$ Aix Marseille Univ, Université de Toulon, CNRS, IM2NP UMR 7334, Yncrea Méditerranée, ISEN-Toulon, Maison du Numérique et de l'Innovation, Place G. \\ Pompidou, 83000 Toulon \\ * Corresponding authors. \\ E-mail addresses : lionel.patrone@im2np.fr (L. Patrone); jean-manuel.raimundo@univ-amu.fr (J.-M. Raimundo)
}

ABSTRACT

\section{Keywords:}

Organic synthesis

Donor-acceptor systems

Push-pull chromophores

Self-assembled monolayers

Electronic properties.
Due to their efficient light absorption properties and their electronic dipole, "push-pull" chromophores with thiophene-based spacer between donor and acceptor groups are very promising for potential use in optoelectronics, photovoltaics, non-linear optics, or electronics. Such applications could benefit from chromophore deposition on a surface in an ordered way with oriented dipoles. For this purpose, self-assembled monolayers (SAMs) constitute an interesting approach. In this work we present a multi-step synthesis of a series of push-pull structures based on 2,2'-bithiophene or dithieno[3,2-b:2',3'-d]thiophene frameworks born on an alkyl chain terminated with an anchoring group for further use in surface modification. Obtained molecules and SAMs were analyzed by cyclic voltammetry, spectroscopy and scanning probe microscopy. We show that varying the acceptor moiety allows to tune the absorption band in a wide spectral range, and that a longer chain length improves the organization of the dipoleoriented chromophore SAM.

\section{Introduction}

Controlled spatial organization of chromophores, by covalent bonding, on solid surfaces has sparked a growing interest in the last decades due to its importance in the field of molecular nanotechnology for the fabrication, for instance, of innovative smart materials and surfaces, and biosensors. ${ }^{1}$ Moreover, the control of the composition and orientation of chromophores at the nanometer scale is of crucial importance in order to optimize both their photophysical and photochemical properties. In this respect, the formation of self-assembled monolayers (SAMs) ${ }^{2}$ appears to be a method of choice to produce robust natureinspired ${ }^{3}$ thin films that are highly ordered, dense, associated with a good uniformity in thickness and in composition.

Among the myriad of chromophores, linear push-pull derivatives (consisting of a $\pi$-conjugated system $(\pi)$ end-capped with a donor (D) on one side and an acceptor (A) on the other side (namely D$\pi-\mathrm{A}))^{4}$ represent one of the most widely studied structures that have been used in several molecular nanotechnology applications comprising non-linear optics (NLO), ${ }^{5}$ organic photovoltaic cells (OPVs), ${ }^{6}$ organic light-emitting diodes (OLEDs), ${ }^{7}$ organic fieldeffect transistors (OFETs) ${ }^{8}$ and so on. However, their grafting onto surface has been still scarcely studied despite their great importance in order to improve the device performances. ${ }^{9}$ As exemplified by Facchetti et al, ${ }^{10} \mathrm{D}-\pi$-A chromophores have been incorporated in insulating monolayers of OFETs, leading to high dielectric constant due to the perfect control of the dipole orientation at the surface (i.e. self-assembled nanodielectrics SANDs). Ashwell et al have sturdily anchored hemicyanines dyes onto a gold surface and have demonstrated a diode-type behavior exhibiting a reversible current rectification upon acidic treatment or dipole inversion. ${ }^{11}$ More recently Meskers et al have proven that the uniform arrangement of the hemicyanine-type dipoles leads to an enhancement of the light harvesting properties associated with an efficient generation of photocurrent ${ }^{12}$ Although these results are very promising and afford interesting properties, the presence of intrinsic charges within these molecules (pyridinium, zwitterion) may be problematic in certain cases because of the existence of coulombic interactions that could alter the self-organization process and/or properties. To circumvent this issue, uncharged linear $\mathrm{D}-\pi$-A chromophores can be considered and used as effective alternatives. ${ }^{13}$ Based on these considerations, we report herein on the behavior of a chromophore SAM grafted on gold surfaces using scanning probe microscopy and spectroscopic methods as well as on the synthesis of a set of new chromophores with several structural modifications that are suitable for surface modifications. 


\section{Results and discussion}

\subsection{Synthesis and SAM characteristics of push-pull chromophores}

Classical linear D- $\pi$-A chromophores can be easily customized in order to improve their intrinsic photophysical properties by selecting the appropriate structural elements. The typical structure of the push-pull chromophores studied in this paper is presented in Scheme 1.

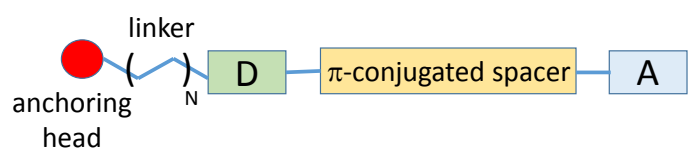

Scheme 1. Structure of the push-pull chromophores studied. The anchoring head is connected to the donor group via a linker (alkyl chain of $2 \mathrm{~N}$ carbon atoms).

In this archetypical molecular structures, electrical and optical properties are determined by the energy of frontier orbitals: the HOMO level is mostly depended on the nature of the donor group while the LUMO level is associated with the acceptor group. Moreover, electron is transferred from the donor (D) to the acceptor (A) through the pi-conjugated spacer acting as an electron relay. Thus tailoring the nature and structure of the spacer for a specific couple of D and A makes it possible to tune the dipole formation ${ }^{14}$. Molecular engineering on $\pi$-conjugated spacers has revealed that planar and rigid systems are highly powerful relays compared to their non-rigid analogues. Hence, design of effective flat rigid electron relay is needed either to modulate the dipole moment and/or to help the spatial organization in order to afford more densely packed layers. Other determinant factors governing the compactness of the monolayers include the length of the linker between the chromophore and the surface, the intermolecular $\pi-\pi$ interactions, the nature of the anchoring group, the surface structure and so on. From a selected family of chromophores we compared at early stage the influence of the chain length on the self-assembling properties by synthetizing two identical chromophores (6-7) possessing the same anchoring group but different linkers. The synthesis is depicted in Scheme 2.

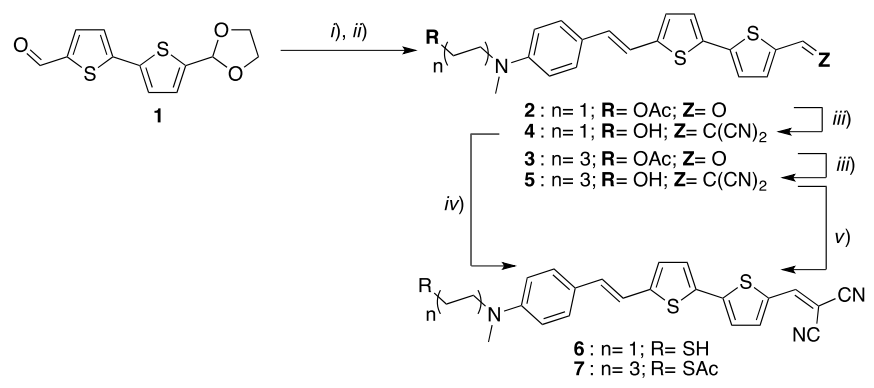

Scheme 2. i) [4-(N-methyl-N-2-acetoxyethylamino)benzyl] - or [4-(Nmethyl-N-6-acetoxyhexylamino)benzyl]- triphenyl-phosphonium bromide, ${ }^{\mathrm{t}} \mathrm{BuOK}, 0^{\circ} \mathrm{C} \mathrm{CH}_{3} \mathrm{CN} / \mathrm{THF}(1: 1) 2.5 \mathrm{~h}$; ii) $\mathrm{HCl} 1 \mathrm{M}$ r.t.1h then $\mathrm{I}_{2}$ cat. $\mathrm{CHCl}_{3}$ reflux 1 h $(2: 94 \% ; 3: 93 \%)$; iii) $\mathrm{NaOH} \mathrm{MeOH} / \mathrm{CH}_{2} \mathrm{Cl}_{2}$, r.t. 3h then $\mathrm{CH}_{2}(\mathrm{CN})_{2}$ DIPEA, EtOH reflux $4 \mathrm{~h}$ for $4(77 \%)$ or $\mathrm{NaOH}, \mathrm{MeOH} / \mathrm{CH}_{2} \mathrm{Cl}_{2}$ TBABr r.t. $3 \mathrm{~h}$ then $\mathrm{CH}_{2}(\mathrm{CN})_{2}, \mathrm{Et}_{3} \mathrm{~N}$ EtOH r.t. 3 h for 5 (95 \%) ; iv) $\mathrm{PBr}_{3} \mathrm{CH}_{2} \mathrm{Cl}_{2}$ r.t. 2 d. then $\mathrm{NaSH}, \mathrm{MeOH} / \mathrm{CH}_{2} \mathrm{Cl}_{2}$ r.t. $\left.18 \mathrm{~h}(6,7 \%) ; v\right) \mathrm{PBr}_{3} \mathrm{CH}_{2} \mathrm{Cl}_{2}$ r.t. 2 d. then $\mathrm{KSAc}, \mathrm{MeOH} / \mathrm{CH}_{2} \mathrm{Cl}_{2}$ r.t. $18 \mathrm{~h}(7,31 \%)$.
The bithiophene derivative $\mathbf{1}$ was synthesized, in $81 \%$ yield, according to a synthetic procedure developed in our group in three steps ${ }^{13}$ from commercially available bithiophene (BT). Then the latter was subjected to a Wittig reaction with the corresponding phosphonium salts (prepared extemporaneously from N-methyl aniline and known procedures) ${ }^{13,15}$ affording the key intermediates $\mathbf{2}$ and $\mathbf{3}$ in $94 \%$ and 93\% yield, respectively. These intermediates were successfully saponified and have been reacted with malonodinitrile (Knoevenagel-type condensation) yielding the chromophores $\mathbf{4}$ and $\mathbf{5}$ in $77 \%$ and $95 \%$ respectively. The last step consists to convert the hydroxyl group into a more active surface-anchoring group such as a thiol or thioacetate group. This was accomplished in two consecutive steps by converting first the $\mathrm{OH}$ group into a more efficient leaving group such as $\mathrm{Br}$ in presence of $\mathrm{PBr}_{3}$ followed by nucleophilic substitution reaction with $\mathrm{NaSH}$ or KSAc leading to the compounds 6 and 7, after purification, in $7 \%$ and $31 \%$, respectively (Scheme 2).
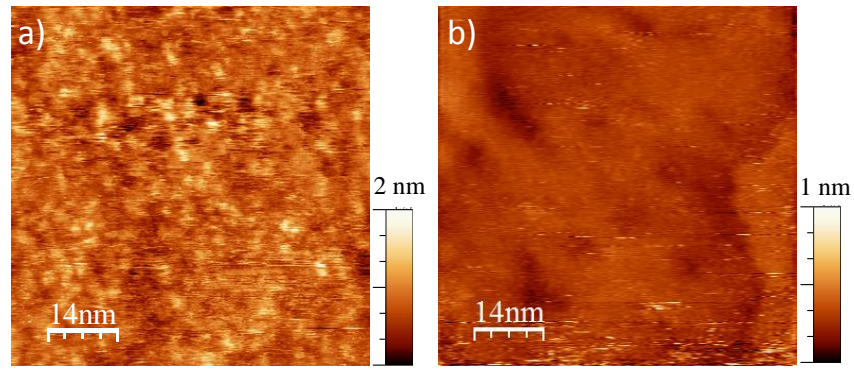

Fig. 1. STM micrographs of obtained SAMs of 6 (a) and 7 (b) after air annealing at $85^{\circ} \mathrm{C}$ during 4 hours and 2 hours respectively. Image sizes are 70 $\mathrm{nm} \times 70 \mathrm{~nm}^{2}$, height scales are indicated on the right.

A successful direct grafting, on pre-cleaned substrates, has been achieved with the chromophores $\mathbf{6}$ and 7 , without any deprotection step in the case of the thioacetate group ${ }^{13,16}$ at room temperature using a $\mathrm{CH}_{2} \mathrm{Cl}_{2}$ solution soak at $1 \mathrm{mM}$ during $24 \mathrm{~h}$. In both cases, complete adsorptions were achieved but slower kinetics was observed for the thioacetate functionalized chromophore 7 as previously speculated. ${ }^{17}$ After grafting, surfaces were abundantly rinsed, dried, and annealed at $85^{\circ} \mathrm{C}$ over few hours to remove solvent traces and to achieve the dense molecular packing.

SAM of 6 appears rougher than SAM of 7 with calculated values of RMS surface roughness of $\sim 0.23 \mathrm{~nm}$ vs. $\sim 0.07 \mathrm{~nm}$ respectively. Indeed, SAM of $\mathbf{6}$ is covered by disordered aggregates appearing as white spots, whereas flat SAM surface of 7 enables to see etch pits (black holes), typical of sulfur reaction with gold surface, as well as gold steps (e.g. right side of the image) thus indicating the presence of a grafted single monolayer. This is further supported by a water contact angle value about closer to that of $\sim 69-75^{\circ}$ reported for single cyano surface group $(\mathrm{CN})^{18}$ for $7\left(\sim 79^{\circ}\right)$ than for $6\left(\sim 88^{\circ}\right)$ for which side groups of disordered tilted molecules should contribute (as a blank, we measured $57^{\circ}$ for cleaned bare gold surface immersed in the solvent). Therefore, although the free thiol-anchoring moiety of compound $\mathbf{6}$ is more reactive, a two-carbon linker appears not long enough to provide the required flexibility for the organization of the SAM. Hence, in the following we will focus on SAMs of compound 7. 


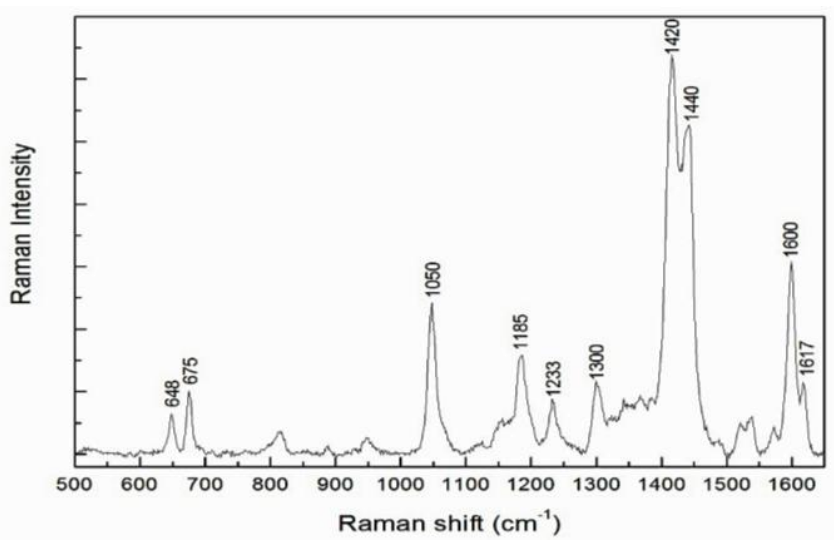

Fig. 2. SERS spectrum of chromophore 7 as SAM on nanostructured gold surface

The surface enhanced Raman spectroscopy (SERS) spectrum of 7 chromophore SAM (Fig. 2) shows a band splitting of the symmetric $\mathrm{C}=\mathrm{C}$ stretching mode of thiophene moieties at 1420 and $1440 \mathrm{~cm}^{-1}$ in respect with the SERS spectra of unsubstituted bithiophene. ${ }^{19}$ Collado et $a .^{20}$ demonstrated that these findings are correlated with a zwitterion form due to the introduction of electron donor and electron withdrawing substituents on the bithiophene core. Thus, donor groups reinforce the $\pi$-conjugated system leading to a vibration mode of the thiophene at higher frequency $\left(1440 \mathrm{~cm}^{-1}\right)$ whereas electron withdrawing groups conduct to a $\mathrm{C}=\mathrm{C}$ vibration at a lower frequency $\left(1420 \mathrm{~cm}^{-1}\right)$. In addition, stretching bands associated with the cyano $(\mathrm{CN})$ groups (at 2000-2300 $\mathrm{cm}^{-1}$ ) are not observed in the spectrum indicating that these groups are not directly in interaction with the gold surface, which is in favor of the speculated chromophores orientation within the SAM, i.e., cyano moieties on top.

Spectroscopic analyses were performed in order to determine the electronic properties of push-pull 7 SAMs on Au. Filled and empty states were studied using Ultraviolet Photoelectron Spectroscopy (UPS) and Inverse Photo-Emission Spectroscopy (IPES) respectively in Fig.3 (for details see reference 21 and references therein). In the UPS spectrum the highest occupied molecular orbital (HOMO) appears as a bump just below the Fermi level. The zoom in the inset shows the HOMO position at $\sim 0.20 \mathrm{eV}$ below the Fermi level. IPES spectrum exhibits clearly a broad band above the Fermi level, the onset of which should correspond to the position of the lowest unoccupied molecular orbital (LUMO), measured at $\sim 1.60 \mathrm{eV}$ above the Fermi level. This indicates the whole push-pull chromophore behaves as a donor with a charge transfer from the molecule to the substrate surface.
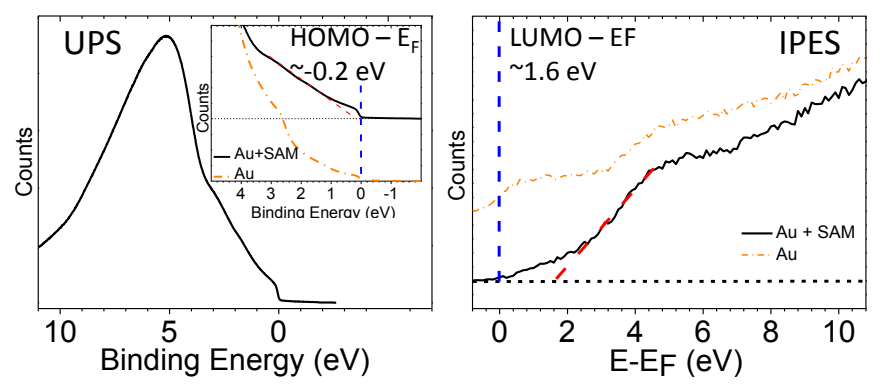

Fig. 3. UPS (left) and IPES (right) spectra of 7 SAMs on gold. Estimated values of HOMO and LUMO were determined by the intersection of the tangent to the band (red dashed line) with the spectrum horizontal baseline (black dotted line). ${ }^{21}$ To bring out LUMO position, IPES spectrum with subtracted background signal is plotted in SI (see Fig. S1).
Based on these results it was demonstrated in this series that hexyl chains, used as linker, are the best candidates for the formation of self-assembled monolayers. These features led us to develop chromophores with different acceptors and spacers in order to possibly control both the electro-optical properties and the density of the monolayers. To this end we focused on changing the bithiophene spacer used for the synthesis of chromophores 6 and 7 with a more rigid and planar one, namely the dithieno[3,2-b:2',3'-d]thiophene (DTT) 8. The DTT $\pi$ conjugated spacer was synthesized in four steps from tetrabromothiophene accordingly to reported procedures. ${ }^{22}$

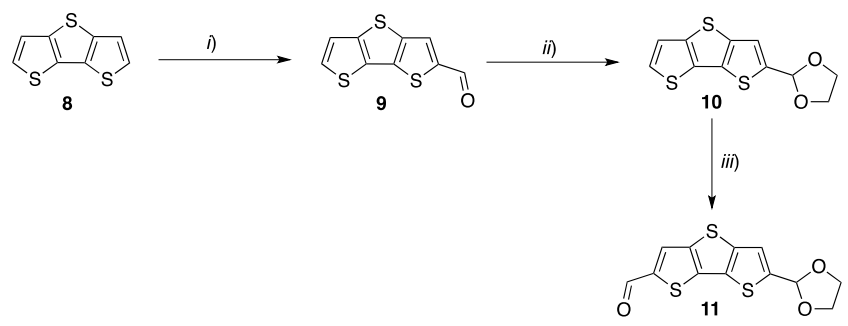

Scheme 3. i) $\mathrm{BuLi},-78^{\circ} \mathrm{C}$ in $\mathrm{THF}, 1 \mathrm{~h}$ then $N$-formylpiperidine $-78^{\circ} \mathrm{C}$ to r.t. (9, 80\%); ii) $\mathrm{HOCH}_{2} \mathrm{CH}_{2} \mathrm{OH}$, PTSA, $\mathrm{C}_{6} \mathrm{H}_{6}$ reflux 2d (10, 97\%); iii) $\mathrm{BuLi}$, $78^{\circ} \mathrm{C}$ in THF, $1 \mathrm{~h}$ then $N$-formylpiperidine $-78^{\circ} \mathrm{C}$ to r.t. $(\mathbf{1 1}, 67 \%)$.

Key derivative $\mathbf{1 1}$ was synthesized in $52 \%$ overall yield from $\mathbf{8}$ in 3 steps following the same procedure as described for compound 1 (Scheme 3). ${ }^{1,23}$ Similarly to the synthesis of compound $\mathbf{3}$ (Scheme 2) the analogous derivative $\mathbf{1 2}$ was obtained in $83 \%$ after purification (Scheme 4). This procedure has the main advantage to afford the desired compounds in significantly higher yields compared to reported procedures using unprotected bisaldehyde spacers $(20-30 \%) .{ }^{24}$ In addition, the ${ }^{1} \mathrm{H}$ NMR analysis of the ${ }^{3} \mathrm{~J}$-coupling constants for the vinylic protons of compounds $\mathbf{3}$ and $\mathbf{1 2}$ (15.75 and $16.0 \mathrm{~Hz}$ respectively) evidences the only presence of the trans-isomers after $\mathrm{I}_{2} / \mathrm{CHCl}_{3}$ treatment. Finally compounds $\mathbf{3}$ and $\mathbf{1 2}$ were reacted with malonodinitrile and/or $\mathrm{N}, \mathrm{N}$-diethyl thiobarbituric acid (DETB) affording derivatives $\mathbf{5}$, 13, 14 and 15, respectively (Scheme 4).

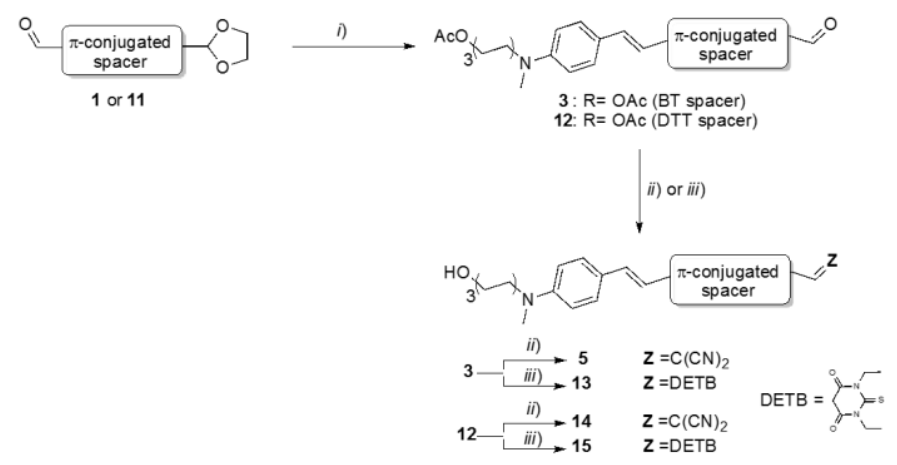

Scheme 4. i) a) [4-(N-methyl-N-6-acetoxyhexylamino)benzyl]triphenylphosphonium bromide ${ }^{\mathrm{BuOK}}, 0^{\circ} \mathrm{C} \mathrm{CH}_{3} \mathrm{CN} / \mathrm{THF}(1: 1) 2.5 \mathrm{~h}$; b) $\mathrm{HCl} 1 \mathrm{M}$ r.t.1h then $\mathrm{I}_{2}$ cat. $\mathrm{CHCl}_{3}$ reflux 1h $(3: 93 \% ; 12: 83 \%)$; ii) $\mathrm{NaOH}, \mathrm{MeOH} / \mathrm{CH}_{2} \mathrm{Cl}_{2}$ TBABr r.t. 3 h then $\mathrm{CH}_{2}(\mathrm{CN})_{2}$, $\mathrm{Et}_{3} \mathrm{~N}$ EtOH r.t. 3 h (5: 95\%; 14: 40\%); iii) $\mathrm{Ac}_{2} \mathrm{O}$ at $80^{\circ} \mathrm{C}, 30 \mathrm{~min}$. then $\mathrm{NaOH}, \mathrm{MeOH} / \mathrm{CH}_{2} \mathrm{Cl}_{2}$ TBABr r.t. 3 h (13: 74\%; 15: $72 \%$ ).

In the last step the $\mathrm{OH}$ group was converted into thioacetate instead of the thiol group in order to avoid its oxidation and to promote stability under storage conditions. The conversion proceeds smoothly but with low yields, probably due to the harsh conditions used during the first step of the reaction (Scheme 5). 
Table 1. Optical properties of compounds 3, 12, 7, 16-18

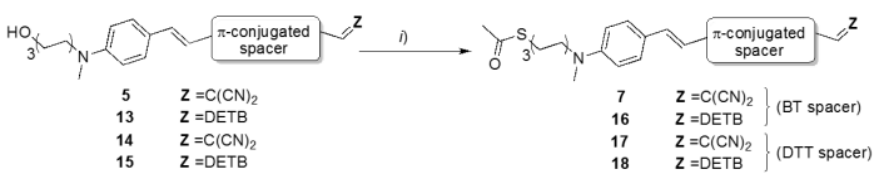

Scheme 5. i) $\mathrm{PBr}_{3} \mathrm{CH}_{2} \mathrm{Cl}_{2}$ r.t. 2 d. then $\mathrm{KSAc}, \mathrm{MeOH} / \mathrm{CH}_{2} \mathrm{Cl}_{2}$ r.t. $18 \mathrm{~h}$ (7: $31 \%$; 16: $15 \%$; 17: $16 \%$; 18: $14 \%$ ).

\subsection{Optical and electrochemical properties of push-pull chromophores}

The optical properties of the new chromophores 3, 12, 7 and 1618 have been investigated by UV-Visible spectroscopy in $\mathrm{CH}_{2} \mathrm{Cl}_{2}$ (Fig. 4, Table 1). In both series, identical behaviors were found and all spectra are characterized by a predominant absorbance band at low energy which is red-shifted when the strength of the electron acceptor is increased successively from the aldehyde $(3$ or 12) to the dicyanovinyl (7 or 17) and then to the $N, N$-diethyl thiobarbituric group (16 or 18). This low energy band corresponds to the intramolecular charge transfer (ICT) band, related to the intrinsic push-pull effect of these structures. Thus, the highest red shift is observed for the derivatives $\mathbf{1 6}$ and $\mathbf{1 8}$ (603 and $604 \mathrm{~nm}$ respectively). Moreover, it is clearly evidenced that the replacement of the BT $\pi$-conjugated spacer by the DTT does not lead to a significant modulation of the absorption properties. Consequently, similar optical bandgaps $\left(\mathrm{E}^{\text {opt }}\right)$ were obtained for the compounds in each series possessing the same acceptor (Table 1). Note that the optical HOMO-LUMO gap of compound $7(\sim 1.9 \mathrm{eV})$ is similar to that obtained from UPS/IPES experiments in Fig. $3(1.8 \mathrm{eV})$.

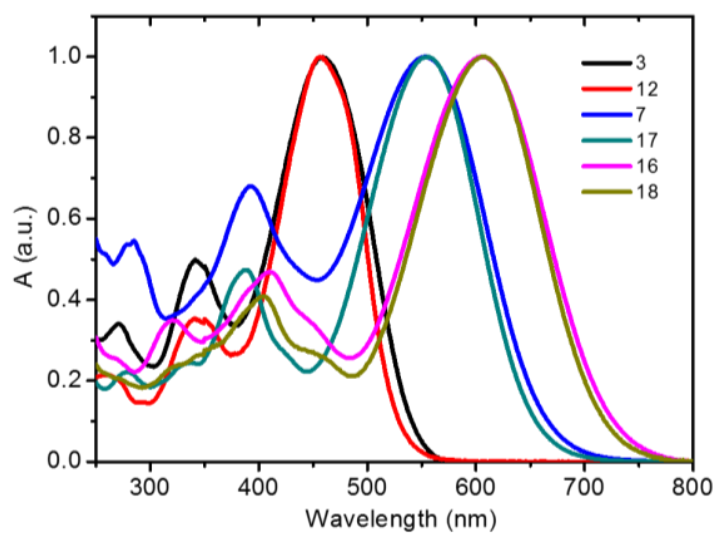

Fig. 4. Normalized UV-Vis absorption spectra of 3, 12, 7, 16-18 in $\mathrm{CH}_{2} \mathrm{Cl}_{2}$

Fluorescence measurements have been performed on these series after excitation at the maximum of absorbance of the ICT band. All chromophores show a high Stokes shift (from 163 to $221 \mathrm{~nm}$ ) after excitation of the emission band associated with low quantum yields that did not exceed $0.10 \%$ (Table 1). Nevertheless, DTT based-chromophores present the highest quantum yields that could be explained by the rigidity and planarity of this $\pi$-spacer leading to a decrease of the energy losses by the internal vibrations. Additionally, as exemplified in Fig. 5, the emission shows a nontrivial band structure having a shoulder. This shoulder could be attributed to the excited internal charge transfer state while the main band is ascribed to the locally excited state. ${ }^{25}$

\begin{tabular}{|c|c|c|c|c|c|c|c|}
\hline & \multicolumn{4}{|c|}{ Absorption } & & \multicolumn{2}{|c|}{ Emission } \\
\hline & $\lambda_{\max }$ & $\varepsilon_{\max }$ & $\lambda_{0-0}$ & $E^{o p t}$ & $\lambda_{\max }$ & $\Delta_{S S}$ & $\phi$ \\
\hline & $(\mathrm{nm})$ & $\left(L . \mathrm{mol}^{-1} \cdot \mathrm{cm}^{-1}\right)$ & $(\mathrm{nm})$ & $(\mathrm{eV})$ & $(\mathrm{nm})$ & $(\mathrm{nm})$ & \\
\hline 3 & 459 & $3.3 .10^{-4}$ & 540 & 2.30 & 640 & 181 & ND \\
\hline 12 & 456 & $3.5 .10^{-4}$ & 526 & 2.36 & 619 & 163 & ND \\
\hline 7 & 550 & $7.5 .10^{-4}$ & 664 & 1.87 & 712 & 162 & 0.042 \\
\hline 17 & 552 & $5.8 .10^{-4}$ & 651 & 1.90 & 736 & 184 & 0.093 \\
\hline 16 & 603 & $3.7 .10^{-4}$ & 723 & 1.71 & 824 & 221 & 0.004 \\
\hline 18 & 604 & $1.1 .10^{-4}$ & 715 & 1.73 & 825 & 221 & 0.015 \\
\hline
\end{tabular}

$E^{o p t}$ optical bandgap; $\Delta_{S s}$ : Stokes shift; ND: not determined; $\phi$ : quantum yield.

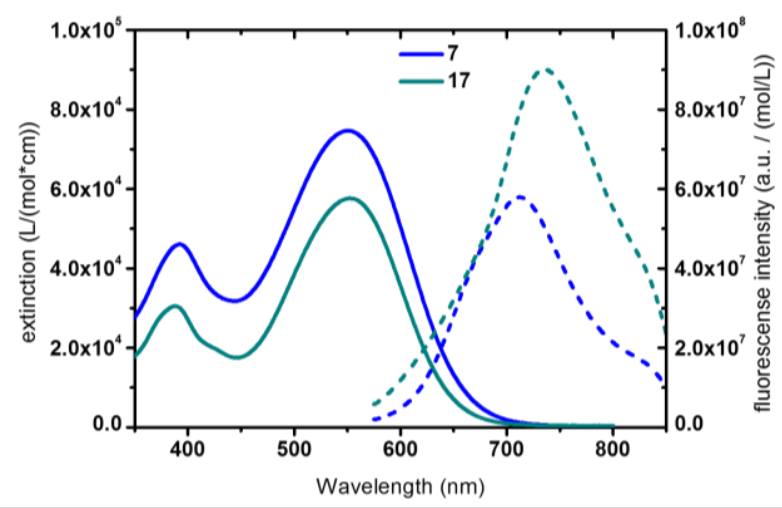

Fig. 5. Absorption (solid line) and emission (dotted line) spectra of 7 (blue) and 17 (dark cyan) in $\mathrm{CH}_{2} \mathrm{Cl}_{2}$. The emission was excited at ICT $\lambda_{\max }(550 \mathrm{~nm}$ for 7 and $553 \mathrm{~nm}$ for 17). Fluorescence intensity was normalized by the concentration $\left(0.75 \cdot 10^{-5} \mathrm{M}\right.$ and $1.07 \cdot 10^{-5} \mathrm{M}$ for 7 and 17 respectively).

Furthermore, vibrational spectra give additional insights about the structure and properties of the above chromophores. For instance, compounds $\mathbf{7}$ and $\mathbf{1 7}$ display a stretching vibration for the $\mathrm{C} \equiv \mathrm{N}$ bond $(v(\mathrm{C} \equiv \mathrm{N}))$ centered at $2220 \mathrm{~cm}^{-1}$ and $2213 \mathrm{~cm}^{-1}$, respectively, which is lowered compared to the expected theoretical value $\left(\sim 2280 \mathrm{~cm}^{-1}\right){ }^{26}$ Thus, these values reflect a strong push-pull effect along the $\pi$-conjugated backbone, which is the most effective in the DTT-bridged chromophores. Stretching vibrations for the $\mathrm{C}=\mathrm{C}$ bonds (specifically those connected to the donor $\left(\mathrm{D} ; v\left(\mathrm{C}_{\mathrm{D}}=\mathrm{C}\right)\right)$ and to the acceptor $(\mathrm{A}$; $\left.v\left(C=C_{A}\right)\right)$ parts $)$ have also been analyzed. Interestingly, the stretching vibrations for the $C_{D}=C$ bonds appear to be the same for all studied chromophores whereas important differences are noticed for the $\mathrm{C}=\mathrm{C}_{\mathrm{A}}$ stretching. These differences have been related to the acceptor strength; indeed a stronger acceptor will lower the frequency of molecular vibration. At the same time, DTT-based chromophores possess lower frequency of $\mathrm{C}=\mathrm{C}_{\mathrm{A}}$ vibration than corresponding BT analogs. This can be explained by less aromatic and more quinoidal nature of DTT-relay (Table 2). 27,28 
Table 2. Evolution of specific stretching vibrations for compounds 7, 16-18.

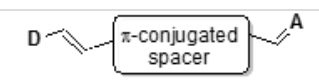

\begin{tabular}{lccc}
\hline & $v(\mathrm{C} \equiv \mathrm{N})\left(\mathrm{cm}^{-1}\right)$ & $v\left(\mathrm{C}_{\mathrm{D}}=\mathrm{C}\right)\left(\mathrm{cm}^{-1}\right)$ & $v\left(\mathrm{C}=\mathrm{C}_{\mathrm{A}}\right)\left(\mathrm{cm}^{-1}\right)$ \\
\hline $\mathbf{7}$ & 2220 & 1597 & 1571 \\
$\mathbf{1 7}$ & 2213 & 1598 & 1558 \\
$\mathbf{1 6}$ & - & 1597 & 1552 \\
18 & - & 1598 & 1550 \\
\hline
\end{tabular}

Analysis of the cyclic voltammograms of compounds 3, 12, 7, 16-18 (Fig. S2 in the Supporting Information) has revealed similar characteristics. All displayed two irreversible oneelectron oxidation redox systems ascribed to formation of the radical cation and dication species and one irreversible oneelectron reduction redox system (Table 3 ). The first oxidation has been attributed to the dialkylaniline donor part (0.660-0.685 V) while the second $(0.97-1.04 \mathrm{~V})$ to the $\pi$-conjugated spacer. The reduction potentials exhibit the main differences, which have been related to the acceptor strengths. However, similar values are obtained when the comparison is made on the spacer changes corroborating the observed optical behaviors.

Table 3. Oxidation and reduction potentials for compounds $3,12,7,16-18$ $10^{-3} \mathrm{M}$ in $\mathrm{CH}_{3} \mathrm{CN} / \mathrm{CH}_{2} \mathrm{Cl}_{2}(1: 1), 0.1 \mathrm{M} \mathrm{Bu}_{4} \mathrm{NPF}_{6}$, Pt (WE) Ag/AgCl (RE), v= $100 \mathrm{mV} / \mathrm{s}, \mathrm{V}$ vs $\mathrm{Fc} / \mathrm{Fc}^{+}$(see Fig. S2 in the Supporting Information for the voltammograms).

\begin{tabular}{|c|c|c|c|c|c|c|}
\hline & $E_{p a(1)}(V)$ & $E_{p a(2)}(V)$ & $E_{p c}(V)$ & HOMO $(\mathrm{eV})$ & LUMO $(\mathrm{eV})$ & $E^{e l e c}(e V)$ \\
\hline 3 & 0.675 & 1.008 & -1.438 & -5.02 & -2.91 & 2.11 \\
\hline 12 & 0.660 & 1.004 & -1.440 & -5.01 & -2.91 & 2.10 \\
\hline 7 & 0.671 & 1.043 & -0.907 & -5.02 & -3.44 & 1.58 \\
\hline 17 & 0.685 & 0.981 & -0.885 & -5.03 & -3.46 & 1.57 \\
\hline 16 & 0.669 & 1.010 & -0.773 & -5.02 & -3.58 & 1.44 \\
\hline 18 & 0.682 & 0.970 & -0.715 & -5.03 & -3.63 & 1.40 \\
\hline
\end{tabular}

Molecular structure of the compounds 7, 16-18 were obtained thanks to DFT calculations using the 6-31G (d,p) basis set (Table $4) .{ }^{29}$ All HOMO levels are located along the $\pi$-conjugated system whereas the LUMO levels are mainly centralized on the BT or DTT core and the lateral acceptor groups. The energy values of these frontier orbitals can be correlated with the cyclic voltammetry experiments for the HOMO levels while calculated LUMO levels appear at higher energies than expected. The main differences could be explained by the fact that in the excited state the molecules exhibit a higher polarization due to the intramolecular charge transfer which is more stabilized by solvation effects in solution leading to lowered LUMO energy levels.
Table 4. HOMO/LUMO calculated values in $\mathrm{eV}$ for compounds 7, 16-18 (B3LYP/ 6-31G(d,p))

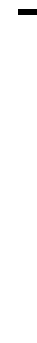

17
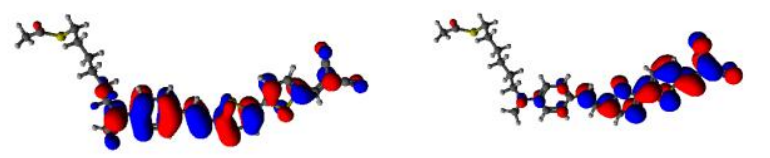

$-5.02$

$-2.88$

16
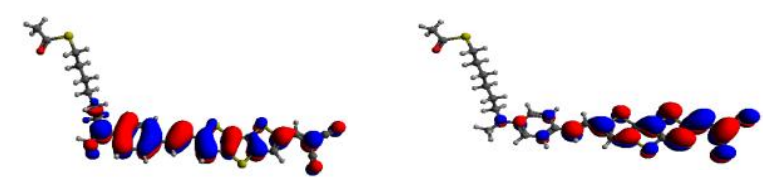

$-5.07$

$-2.86$

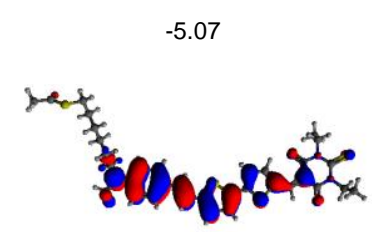

$-4.95$

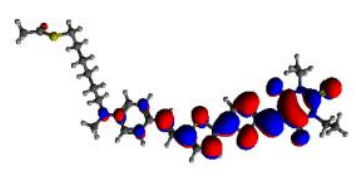

$-2.84$

18
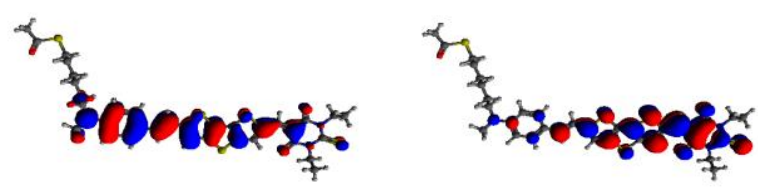

$-2.83$

\section{Conclusion}

Previously published works on donor-acceptor chromophores for surface modification ${ }^{10-12}$ deal with charged compounds for which coulombic interactions could hinder the self-organization process and/or alter the properties of the functionalized surface, and surface modification has been scarcely studied. Conversely, in this study we have reported on an innovative approach with the synthesis of uncharged novel D- $\pi$-A linear chromophores that are suitable for surface modifications, and a global engineering of the electrical and optical properties using different structural modifications namely the $\pi$-conjugated spacer, the acceptor, and the donor. Moreover their SAMs have also been analyzed. Although the donor part remains the same for all synthesized chromophores (aniline analogues) preliminary slight changes on the length of the alkyl chain ( 2 or 6 carbons) have been tested revealing a suitable chain length of $2<\mathrm{n} \leq 6$ carbon atoms for successful self-assembled monolayer formation, as evidenced by both spectroscopic and microscopy studies. SAMs of molecule 7 were studied by UPS and IPES spectroscopies demonstrating a good conformity of modified surface electronic properties with molecular characteristics of the adsorbed chromophore (e.g. HOMO- LUMO bandgap from optical and electrochemical analyses). Based on these results a set of chromophores associated with various optical properties has been built around this optimized donor in combination with different acceptors and electron relays (BT or DTT). It has been shown that solely increasing the acceptor strength in these push-pull chromophores enables to tune the absorption in a wide visible spectral range from the blue $(\sim 450 \mathrm{~nm})$ to the red $(\sim 600 \mathrm{~nm})$. To our knowledge it is the first time such an effect has been shown which makes these molecules very promising for applications such as organic photovoltaic devices. ${ }^{6}$ For such applications where a broad 
spectral absorption range is mandatory, it should be benefit to mix chromophores with complemental absorption in the SAM. We are currently working on a smart approach for that with organized SAMs of bi-chromophoric moieties borne on the same anchoring group. Interestingly and as expected, the replacement of the BT $\pi$-conjugated spacer by its more planar and rigid analogue DTT has been shown not to improve the optical properties. Nevertheless, the insertion of such rigid spacer might be useful to form more dense monolayers. On this subject also, works are currently under progress. In addition, future analyses could interestingly concern optical properties of the SAMs using reflection absorption spectroscopy and spectroscopic ellipsometry. ${ }^{30}$

\section{Experimental section}

All chemicals were purchased from Sigma-Aldrich, TCI-Europe or Alfa Aesar and used as received from their commercial sources, unless otherwise stated, without further purification. Infrared spectra were recorded on an Agilent Cary 630 FTIR spectrometer. UV-visible absorption spectra were obtained on a Varian Cary 1E spectrophotometer. The electronic absorption maxima $\left(\lambda_{\max }\right)$ are directly extracted from absorption spectra of the chromophore-based solution. Fluorescence emission spectra were recorded on a Varian Cary Eclipse spectrophotometer, relative fluorescence quantum yields were determined by measuring fluorescence of anthracene as a reference. ${ }^{1} \mathrm{H}$ and ${ }^{13} \mathrm{C}$ NMR spectra were recorded on Bruker AC 250 at $250 \mathrm{MHz}$ and $62.5 \mathrm{MHz}$, respectively. ${ }^{1} \mathrm{H}$ NMR data are reported as follows: chemical shifts in parts per million relative to $\mathrm{CHCl}_{3}(7.26 \mathrm{ppm})$, multiplicity (s, singlet; $d$, doublet; $t$, triplet; $q$, quartet; $\mathrm{m}$, multiplet; br, broadened), coupling constant (Hz), and integration. High-resolution mass spectroscopy was made with a Qstar Elite spectrometer (Applied Biosystems SCIEX) with ionization electrospray source (ESI) through the Spectropole facility of Aix-Marseille University. ${ }^{31}$ All reactions were magnetically stirred and monitored by thin-layer chromatography (TLC) using E. Merck silica gel 60 F254 precoated plates $(0.25$ $\mathrm{mm})$, and flash chromatography was performed on silica gel 60 (230-400 mesh) from Macherey-Nagel. Compounds $\mathbf{1}^{13}, \mathbf{3}^{93}, \mathbf{7}^{13}$, $\mathbf{8}^{16}, \mathbf{9}^{22,32}, \mathbf{1 0}^{16}$ have been prepared according to previously' described procedures and their spectroscopic characterizations gave satisfactory analyses. Cyclic voltammetry (CV) data were acquired using a BAS 100 Potentiostat (Bioanalytical Systems) and a PC computer containing BAS100W software (v2.3). A three-electrode system based on a platinum $(\mathrm{Pt})$ working electrode (diameter $1.6 \mathrm{~mm}$ ), a Pt counter electrode and an $\mathrm{Ag} / \mathrm{AgCl}$ (with $3 \mathrm{M} \mathrm{NaCl}$ filling solution) reference electrode was used. Tetrabutylammonium hexafluorophosphate (n$\mathrm{Bu}_{4} \mathrm{NPF}_{6}$ ) (Fluka) was used as received and served as supporting electrolyte $(0.1 \mathrm{M})$. All experiments were carried out in $\mathrm{CH}_{3} \mathrm{CN} / \mathrm{CH}_{2} \mathrm{Cl}_{2}(1: 1)$ (electronic grade purity) at $20^{\circ} \mathrm{C}$. Ferrocene was used as internal standard. Electrochemical reduction/oxidation potential values were determined from the cyclic voltammogram at a concentration of $1.10^{-3} \mathrm{M}$ with a scan rate of $100 \mathrm{mV} \cdot \mathrm{s}^{-1}$. Calculations were carried out with the Gaussian 09 program.

STM (Multimode 8 \& Nanoscope V, from Bruker) was operated using $\mathrm{Pt} / \mathrm{Ir}$ cut tips with tunneling resistance $\mathrm{R}_{\mathrm{th}} \geq 100 \mathrm{G} \Omega$ (typically $\mathrm{I} \sim 2 \mathrm{pA}, \mathrm{V} \sim 1 \mathrm{~V}$ ) in order to be able to resolve the molecular structures without entering the SAM. Voltage was applied to the sample with respect to the grounded tip. For such analyses, SAMs of the different thiol- or thioacetate-terminated chromophores were prepared on atomically flat $\mathrm{Au}(111)$ substrates on mica either purchased from Scientec or prepared at IM2NP. These SAMs on flat gold represent a model system to study the arrangement of molecules and the grafting process thanks to the presence of typical etch pits in the gold surface resulting from the sulfur to gold interaction. ${ }^{33}$
Surface enhanced Raman spectroscopy (SERS) measurements were conducted on the SAM of the chemisorbed chromophore 7 onto a nanostructured gold thin film. The SERS active surface is obtained by thermal evaporation under high vacuum $\left(10^{-6} \mathrm{mbar}\right)$ of the gold film (7 nm thick) on a glass substrate. SERS spectrum was recorded at room temperature with a Raman spectrometer (Labram HR800- Jobin Yvon) using the $632.4 \mathrm{~nm}$ excitation line of a $\mathrm{He}-\mathrm{Ne}$ laser in retrodiffusion geometry. The laser beam was focused through a $\mathrm{x} 50$ objective $(50 \mathrm{x})$ to a spot around $1 \mu^{2}$. Spectral calibration was performed on silicon samples at $520 \mathrm{~cm}^{-}$

Ultraviolet Photoelectron Spectroscopy (UPS) was operated with an Omicron equipment (EA125 electron analyzer) and a UV source using the HeI line $(21 \mathrm{eV})$ at normal incidence. Inverse Photo-Emission Spectroscopy (IPES) experiments were performed at normal incidence in the isochromat mode, detecting photons of around $9.7 \mathrm{eV}$. The absorbed current was kept low enough $(\sim 1 \mu \mathrm{A}$ range $)$ to prevent any degradation of the molecules as monitored by a constant signal level for each of the ten spectra that were accumulated.

\section{Acknowledgements}

The authors thank gratefully Prof. J.-J. Simon for valuable discussions on this work and Prof. M. Abel for UPS analyses. This work was supported by the Centre National de la Recherche Scientifique (CNRS) and the Ministère de l'Enseignement Supérieur et de la Recherche. Financial support from ANR program (SAGe III-V project ANR-11-BS10-012) and "Solutions Communicantes Sécurisées" (SCS) competitive cluster are also acknowledged. V.M. also thanks the Ministère de l'Enseignement Supérieur et de la Recherche for his doctoral Financial support.

\section{References}

1. (a) Martin, T. A.; Herman, C. T. ; Limpoco, F. T. ; Michael, M. C. ; Potts, G. K. ; Bailey, R. C. ACS Appl. Mater. Interfaces, 2011, 3, 37623771; (b) Fan, R. ; Vermesh, O. ; Srivastava, A. ; Yen, B. K. H. ; Qin, L. ; Ahmad, H. ; Kwong, G. A. ; Liu, C.-C. ; Gould, J. ; Hood, L. ; Heath, J. R. Nat. Biotechnol., 2008, 26, 1373-1378; (c) Braunschweig, A. B. ; Huo, F. ; Mirkin, C. A. Nat. Chem., 2009, 1, 353-358 ; (d) Pauloehrl, T. ; Welle, A. ; Bruns, M. ; Linkert, K. ; Bçrner, H. G. ; Bastmeyer, M. ; Delaittre, G. ; Barner-Kowollik, C. Angew. Chem. Int. Ed., 2013, 52, 9714-9718; (e) Pezzato, C. ; Maiti, S. ; Chen, J. L.-Y. ; Cazzolaro, A.; Gobbo, C.; Prins, L. J. Chem. Commun., 2015, 51, 9922-9931.

2. (a) Lee, H. J.; Jamison, A. C. ; Lee, T. R. Acc. Chem. Res., 2015, 48, 3007-3015 ; (b) Love, J.C. ; Estroff, L.A. ; Kriebel, J. K. ; Nuzzo, R. G. ; Whitesides, G. M. Chem. Rev., 2005, 105, 1103-1169 ; (c) Kumar, R. J.; Churches, Q. I.; Subbiah, J.; Gupta, A.; Ali, A.; Evans, R. A.; Holmes, A. B. Chem. Commun., 2013, 49, 6552-6554; (d) Ha, Y.G.; Facchetti, A.; Marks, T. J. Chem. Mater., 2009, 21, 1173-1175.

3. (a) Boynton, R. M. Human Color Vision, Holt, Rinehart and Winston, New York, 1979 ; (b) Scholes, G. D.; Fleming, G. R.; Olaya-Castro, A.; van Grondelle, R. Nat. Chem., 2011, 3, 763-774

4. Bureš, F. RSC Adv., 2014, 4, 58826-58851.

5. Liu, J.; Gao, W.; Kityk, I.; Liu, X.; Zhen, Z. Dyes Pigm., 2015, 122, 7484.

6. Malytskyi, V; Simon, J.-J.; Patrone, L.; Raimundo, J.-M. $R S C A d v$., 2015, 5, 354-397.

7. Zhu, X.-H.; Peng, J.; Cao, Y.; Roncali, J. Chem. Soc. Rev., 2011, 40, 3509-3524.

8. Ponce Ortiz, R.; Herrera, H.; Mancheño, M. J.; Seoane, C.; Segura, J. L.; Mayorga Burrezo, P.; Casado, J.; López Navarrete, J. T.; Facchetti, A.; Marks, T. J. Chem. Eur. J., 2013, 19, 12458-12467.

9. (a) Lee, O. P.; Yiu, A. T.; Beaujuge, P. M.; Woo, C. H.; Holcombe, T. W.; Millstone, J. E.; Douglas, J. D.; Chen, M. S.; Fréchet, J. M. J. Adv. Mater., 2011, 23, 5359-5363; (b) Li, H.; Choi, J.; Nakanishi, T. Langmuir, 2013, 29, 5394-5406; (c) Yagai, S.; Goto, Y.; Lin, X.; Karatsu, T.; Kitamura, A.; Kuzuhara, D.; Yamada, H.; Kikkawa, Y.; Saeki, A.; Seki, S. Angew. Chem. Int. Ed. Engl., 2012, 51, 6643-6647.

10. (a) Yoon, M.-H.; Facchetti, A.; Marks, T.J. Proc. Natl. Acad. Sci. USA, 2005, 102, 4678-4682; (b) Di Benedetto, S.A.; Frattarelli, D. L. ; Facchetti, A. ; Ratner, M. A. ; Marks, T. J. J. Am. Chem. Soc., 2009, 131, 
11080-11090.

11. (a) Ashwell, G. J.; Tyrrell, W. D.; Whittam, A. J. J. Mater. Chem., 2003 13, 2855-2857; (b) Ashwell, G. J.; Robinson, B. J.; Amiri, M. A.; Locatelli, D.; Quici, S.; Roberto, D. J. Mater. Chem., 2005, 15, 42034205; (c) Ashwell, G. J.; Mohib, A. J. Am. Chem. Soc., 2005, 127, 16238-16244; (d) Ashwell, G. J.; Urasinska, B.; Tyrrell, W. D. Phys. Chem. Chem. Phys., 2006, 8, 3314-3319.

12. Vijayaraghavan, R. K.; Gholamrezaie, F.; Meskers, S. C. J. J. Phys. Chem. C, 2013, 117, 16820-16829.

13. Malytskyi, V; Simon, J.-J.; Patrone, L.; Raimundo, J.-M. $R S C A d v$., 2015, 5, 26308-26315.

14. Mandal, K.; Chattopadhyay, T.; Nandi, P.K.; Bhattacharyya, S.P. Indian J. Chemistry -Section A, 2003, 42A, 449-459; Dalton, L.R.; Pure Appl. Chem., 2004, 76 (7-8), 1421-1433.

15. (a) Robello, D. R. ; Perry, R. J. ; Urankar, E. J. ; Macromolecules, 1993 26, 6940-6944 ; (b) Maertens, C.; Zhang, J.-X.; Dubois, P.; Jerome, R. J. Chem. Soc., Perkin Trans.2, 1996, 4, 713-718; (c) Raimundo, J.-M.; Blanchard, P.; Gallego-Planas, N.; Mercier, N.; Ledoux-Rak, I.; Hierle, R.; Roncali, J. J. Org. Chem., 2002, 67, 205-218.

16. (a) Kang, Y.; Won, D.-J. ; Kim, S. R. ; Seo, K. ; Choi, H.-S. ; Lee, G. Noh, Z. ; Lee, T. S. ; Lee, C. Mater. Sci. Eng., C, 2004, 24, 43-46 ; (b) Nakashima, H. ; Furukawa, K ; Ajito, K. ; Kashimura, Y. ; Torimitsu, K. Langmuir, 2005, 21, 511-515.

17. Béthencourt, M. I. ; Srisombat, L.-O.; P. Chinwangso, P. ; Lee, T. R. Langmuir, 2009, 25, 1265-1271.

18. Laibinis, P.E.; Whitesides, G.M. J. Am. Chem. Soc. 1992, 114, 9022-9028

19. Sarkar, Uttam K.; Chakrabarti, S.; Misra, T. N.; Pal, A. J. Chem. Phys. Lett, 1992, 200, 55-59

20. Collado, D. ; Casado, J. ; Gonzalez, S. R.; Navarrete, J. T. L. ; Suau, R. ; Perez-Inestrosa, E. ; Pappenfus, T. M.; Raposo, M. M. M. Chem. Eur. J., 2011, 17, 498-507.

21. Lefèvre, X. ; Moggia, F. ; Segut, O. ; Lin, Y.-P. ; Ksari, Y. ; Delafosse, G. ;Smaali, K. ; Guérin, D. ; Derycke, V. ; Vuillaume, D. ; Lenfant, S. ; Patrone, L. ; Jousselme, B. J. Phys. Chem. C, 2015, 119, 5703-5713.

22. Frey, J.; Proemmel, S.; Armitage, M. A.; Holmes, A. B. Org. Synth 2006, 83, 209-216.

23. Li, S.-R.; Lee, C.-P. ; Yang, P.-F.; Liao, C.-W.; Lee, M. M.; Su, W.-L.; Li, C.-T.; Lin, H.-W.; Ho, K.-C.; Sun, S.-S. Chem. Eur. J., 2014, 20 10052-10064.

24. Kim, O.; Fort, A.; Barzoukas, M.; Blanchard-Desce, M.; Lehn, J.-M. J. Mater. Chem. 1999, 9, 2227-2232.

25. Lapouyade, R.; Czeschka, K.; Majenz, W.; Rettig, W.; Gilabert, E.; Rulliere, C. J. Phys. Chem. 1992, 96, 9643-9650.

26. Ruiz Delgado, M. C.; Hernández, V.; Casado, J.; López Navarrete, J. T.; Raimundo, J.-M.; Blanchard, P.; Roncali, J. J. Mol. Struct. 2003, 651$653,151-158$

27. Tan, C.-J. ; Yang, C.-S. ; Sheng, Y.-C. ; Wika Amini, H.; Gavin Tsai, H.H. J. Phys. Chem. C 2016, 120, 21272-21284

28. Casado, J.; Hernández, V.; Kim, O.-K.; Lehn, J.-M.; López Navarrete, J.T.; Delgado Ledesma, S.; Ponce Ortiz, R.; Ruiz Delgado, M.C.; Vida, Y.; Pérez-Inestrosa, E. Chemistry - A European Journal 2004, 10 (15), 3805-3816

29. Frisch, M. J.; Trucks, G. W.; Schlegel, H. B.; Scuseria, G. E.; Robb, M. A.; Cheeseman, J. R.; Scalmani, G.; Barone, V.; Mennucci, B.; Petersson, G. A.; Nakatsuji, H.; Caricato, M.; Li, X.; Hratchian, H. P.; Izmaylov, A. F.; Bloino, J.; Zheng, G.; Sonnenberg, J. L.; Hada, M.; Ehara, M.; Toyota, K.; Fukuda, R.; Hasegawa, J.; Ishida, M.; Nakajima, T.; Honda, Y.; Kitao, O.; Nakai, H.; Vreven, T.; Montgomery, J. A., Jr.; Peralta, J. E.; Ogliaro, F.; Bearpark, M.; Heyd, J. J.; Brothers, E.; Kudin, K. N.; Staroverov, V. N.; Kobayashi, R.; Normand, J.; Raghavachari, K.; Rendell, A.; Burant, J. C.; Iyengar, S. S.; Tomasi, J.; Cossi, M.; Rega, N.; Millam, J. M.; Klene, M.; Knox, J. E.; Cross, J. B.; Bakken, V.; Adamo, C.; Jaramillo, J.; Gomperts, R.; Stratmann, R. E.; Yazyev, O.; Austin, A. J.; Cammi, R.; Pomelli, C.; Ochterski, J. W.; Martin, R. L.; Morokuma, K.; Zakrzewski, V. G.; Voth, G. A.; Salvador, P.; Dannenberg, J. J.; Dapprich, S.; Daniels, A. D.; Farkas, Ö.; Foresman, J. B.; Ortiz, J. V.; Cioslowski, J.; Fox, D. J. Gaussian 09, Revision D.01, Gaussian, Inc., Wallingford CT, 2009.

30. Toccafondi C.; Prato. M.; Maidecchi G.; Penco A. ; Bisio F. ; Cavalleri O. ; Canepa M., J. Coll. Int. Sci. 2011, 364, 125-132.

31. For more information, see website of Spectropôle from Aix-Marseille University: http://www.spectropole.u-3mrs.fr/presentation0.htm

32. Zhang, L.; Tan, L.; Hu, W.; Wang, Z. J. Mater. Chem., 2009, 19, 82168222.

33. (a) Tour, J. M.; Jones II, L.; Pearson, D. L.; Lamba, J. J. S.; Burgin, T. P.; Whitesides, G. M.; Allara, D. L.; Parikh, A. N.; Atre, S. V. J. Am. Chem. Soc.,1995, 117, 9529-9534; (b) Kang, J. F. ; Ulman, A. ; Liao, S. Jordan, R. ; Yang, G. ; Liu, G.-Y. Langmuir, 2001, 17, 95-106. 